\title{
SHARING BUDGETARY AUSTERITY UNDER FREE MOBILITY AND ASYMMETRIC INFORMATION: AN OPTIMAL REGULATION APPROACH TO FISCAL FEDERALISM
}

\author{
MARIE-LAURE BREUILLÉ \\ ROBERT J. GARY-BOBO \\ CESIFO WORKING PAPER NO. 1559 \\ CATEgORY 1: PubliC FinANCE \\ OCTOBER 2005 \\ An electronic version of the paper may be downloaded \\ - from the SSRN website: \\ www.SSRN.com \\ - from the CESifo website: \\ www.CESifo-group.de
}




\title{
SHARING BUDGETARY AUSTERITY UNDER FREE MOBILITY AND ASYMMETRIC INFORMATION: AN OPTIMAL REGULATION APPROACH TO FISCAL FEDERALISM
}

\begin{abstract}
In the present article, Tiebout meets Laffont and Tirole in the land of Fiscal Federalism. We use a non-trivial Principal-Multi-Agent model to characterize the optimal intergovernmental grant schedule, when the cost of local public goods depends on hidden characteristics and actions of local governments, and under citizen free mobility. We show that local governments earn informational rents, and how optimal local taxes, public good production levels and land prices are jointly distorted at the second-best optimum, as a consequence of free mobility and asymmetric information. The effect of informational asymmetries is to decrease the average production of public goods and to increase the inter-jurisdictional variance of taxes and public-good production.
\end{abstract}

JEL Code: D72, D82, H7.

Keywords: asymmetric information, Principal-Agent model, public budget deficits, freemobility equilibrium, fiscal federalism.

\author{
Marie-Laure Breuillé \\ THEMA \\ University of Paris $X$-Nanterre \\ 200, avenue de la République \\ 92001 Nanterre Cedex \\ France \\ m.breuille@u-paris10.fr
}

\author{
Robert J. Gary-Bobo \\ TEAM \\ University of Paris 1 Panthéon-Sorbonne \\ 106-112 boulevard de l'Hôpital \\ 75647 Paris Cedex 13 \\ France \\ garybobo@univ-paris1.fr
}

The authors thank Sven Feldmann, Guy Gilbert, Hubert Kempf, Pierre Picard and Emmanuelle Taugourdeau for remarks and suggestions. 


\section{Introduction}

Since Tiebout's (1956) seminal work, the extent to which citizens' free mobility helps mitigating inefficiencies in the allocation of local public goods has been studied in various contexts ${ }^{1}$. In the present article, Tiebout meets Laffont and Tirole ${ }^{2}$ in the land of Fiscal Federalism ${ }^{3}$. We study a non-trivial Principal-Multi-Agent problem in which the Principal is a central government, the Agents are local governments, and in which citizens are free to move from one jurisdiction to the other. In each jurisdiction, there is a land market, the local government chooses a local tax, and the production level of a local public good. Local governments are rent and reelection-seeking politicians, with a clear incentive to pump out money from the central government. Any change in local public policies may trigger population movements, changing local tax revenues, and therefore local deficits. The central government's policy objective is to minimize the cost of transfers to local governments - i.e., the total sum of grants - plus any financial costs or interest charges associated with public deficits, subject to the local governments' individual rationality constraints, and subject to the constraints of a free-mobility equilibrium. This deficit minimization problem is shown to be equivalent to maximization of the sum of local governments' utilities, and characterizes optimality in a certain sense. We study this problem under asymmetric information: the center cannot disentangle the impact of unobserved local conditions and unobservable cost-reduction efforts of the local government on the cost of local public goods. We analyze the second-best optimal contract, called the "internal stability pact", in this Principal-Multi-Agent setting. The solution gives an optimal grant function, as well as local production levels and tax rates.

Our approach thus combines elements of Political Economy with optimal regulation theory. By Political Economy, we mean that the local governments' objectives do not try to maximize the citizens' welfare, but maximize instead a politician's utility function in which reelection probability and rents enter as arguments. In addition, we study a benchmark variant of the model in which local governments are benevolent welfare maximizers. Finally, our central government has no aversion for inequality, and thus no redistribution motive: we

\footnotetext{
${ }^{1}$ For a recent survey of the literature on local public goods, see Scotchmer (2001).

${ }^{2}$ See Laffont and Tirole (1986), (1993).

${ }^{3}$ See the classic contribution, Oates (1972), and for a more recent survey of the field, see Oates (2004).
} 
therefore isolate a pure efficiency problem.

Our results can be summarized as follows. In the complete information case, we derive the optimal grant schedule, in both the "Political Economy" and "Welfare Maximization" variants of the model. The first-order conditions for this problem form a complex system of integral equations, that can be solved analytically in the linear-quadratic case. We discuss the meaning of these equations and then focus on the linear-quadratic case, in which the optimal grant can be fully derived. Optimal local public-good productions, taxes, costreduction efforts, and land prices are decreasing functions of the jurisdiction's marginal cost type; the optimal grant schedule is a cost-reimbursement rule that leaves a zero rent to all local governments. If citizens are made more mobile, the inter-jurisdictional variances of taxes and public productions do increase. Comparison of the "Political Economy" with the "Welfare Maximization" solution shows that the two variants are in fact qualitatively very similar.

Under asymmetric information, the central government can observe local unit costs of production, but cannot disentangle the contribution of "natural" conditions (i.e., the type), from the effect of cost-reduction efforts. A higher type corresponds to a higher marginal cost of production, ceteris paribus. There is a continuum of possible local conditions, or types, described by a given probability distribution. Incentive compatibility requires the payment of an informational rent, which is decreasing with type, to all local governments, except the least efficient one. All local governments contribute to deficit reduction efforts (i.e., share "budgetary austerity"), and not only those who run a deficit. Second-best optimal local productions and taxes are decreasing functions of the jurisdiction type (in fact of the "virtual type"), with joint distortions of taxes and productions. The effect of informational asymmetries is to reduce average production, and to increase the variance of both local productions and taxes. The citizen's average utility is smaller under asymmetric information, as compared to the complete information benchmark. The results obtained are very different from the case of immobile consumers, in which the model boils down to a standard PrincipalAgent model. In the free-mobility case, there is a distortion "at the top" (i.e., for the most efficient jurisdiction), and local taxes are distorted too. The interplay of taxes, land prices and public good productions is more subtle in the case of free mobility. 


\section{Relationship with the literature}

In a recent survey of Fiscal Federalism, Oates (2004), describes the evolution of the field, since the early classic work, as a progressive synthesis using elements coming from other literatures. The theory had first to react to its Public-Choice school critics, and had to amend or remove the government benevolence assumptions used in the classic normative approaches ${ }^{4}$. In the past decade, concepts and techniques from information economics, the theory of incentives and the theory of the firm, have been imported in the field. Important recent work poses the problem of the optimal degree of decentralization; see for instance Gilbert and Picard (1996), Lockwood (2002), Besley and Coate (2003), Laffont and Zantman (2002) ${ }^{5}$. The theory of the firm and more particularly, the theory of incomplete contracts, has been applied to the question of decentralization; see J. Cremer et al. (1996); Seabright (1996). Finally, Principal-Agent theory has been a source of inspiration for a number of recent papers devoted to decentralization and fiscal redistribution in a federation, or a multi-jurisdictional model; among other contributions, e.g., Persson and Tabellini (1996), Cremer, Marchand and Pestieau (1996), Raff and Wilson (1997), Bucovetsky, Marchand and Pestieau (1998), Lockwood (1999), Boadway, Horiba and Jha (1999), Bordignon, Manasse and Tabellini (2001), Cornes and Silva (2002), Besfamille (2002).

Some of these papers deal with the incentives when tasks, such as public works, must be delegated to local agents (Boadway et al. (1999), Besfamille (2002)). A number of other contributions have focused on inter-regional redistribution (or insurance) problems. Cremer et al. (1996) study a federation in which members possess two unobserved characteristics: income and taste for public goods. They perform an optimal tax analysis of this economy and show that second-best optimal redistribution is limited by informational problems. Bucovetsky et al.(1998) consider again the optimal subsidy problem in a federation in which members differ by their preferences for public goods, when local governments rely on capital income taxation. They show that distortions in both the allocation of capital and the production of public goods are the result of the center's incomplete information.

Raff and Wilson (1997) consider the income redistribution problem between regions in

\footnotetext{
${ }^{4}$ For a survey of these approaches, see Inman and Rubinfeld (1997).

${ }^{5}$ These papers offer various theories of the trade-off between centralization and decentralization.
} 
the presence of mobile workers, when the local productivity of work, which is not observed by the center, depends on some public effort (costly public inputs) which is also unobservable. Lockwood (1999) studies an inter-regional optimal insurance problem, in which risk-averse regions are subject to privately observed random shocks of various types. He studies optimal grants when there are public-good spillovers between regions, and shows the existence of a "two-way distortion" of public production, i.e., there can be oversupply as well as undersupply with respect to the first-best production rule, depending on the value of the shock. Cornes and Silva (2002) study the optimal interregional redistribution problem when the cost of providing local public goods is the difference between an unknown type and unobserved local government effort; they find analogous results: distortions of both cost-reducing efforts and local public good production.

As compared to the articles cited above, the present contribution considers the optimal grant problem in the case of a continuum of unobservable jurisdictions types, combined with perfectly mobile citizens, local land markets, and fiscal externalities due to population migrations. This gives rise to a genuine Principal-Multi-Agent model, and, as far as we know, this has not been done before. Raff and Wilson's (1997) pioneering work considers worker mobility, but only two types of jurisdictions, with no interdependent land or real estate markets, and no fiscal externalities. Cornes and Silva (2002) and Lockwood (1999) have analyzed a Principal-Agent model in the continuum-of-types case, but with immobile representative consumers. A study of the continuum-of-types model is of course useful, to the extent that it allows a better understanding of the optimal grant function's properties, with a realism that the illustrative two-types case doesn't possess. In addition, our (relatively) simple model has a normative, (i.e, welfare maximization) and a "positive" (i.e; "Political Economy") variant, that can easily be compared.

We think that Laffont and Tirole's (1986) model is well-adapted to study the problem delineated above. Budgetary efforts, whether they take the form of (local) tax increases or of reductions in local public good production, are unpopular. The vote maximizing behavior of local politicians will lead them to exert a sub-optimal level of deficit-reduction effort, from the central government's point of view. The central government's ability to provide correct incentives to local governments essentially depends on the information it possesses, and this 
can vary form one country to the other. In many countries, the central government levies local taxes on behalf of local authorities, who vote on local tax rates. Due to this particular form of organization (tax collection monopoly of the center), the central government is necessarily endowed with many pieces of information (on local tax rates, tax bases, and budgets) and can try to curb local public expenditure via its grants to local public authorities. Due to the fact that local budgets are public information, the center observes total cost, as well as the quantity of public goods produced locally, but cannot distinguish which part of the cost can be attributed to effort and which part depends on hidden local conditions: this precisely corresponds to Laffont and Tirole's (1986) model of optimal regulation under asymmetric information, that we adapted to our setting.

Our analysis has been motivated by the desire to study the internal consequences of EU agreements for euro-zone states, which is one among several other possible applications. The new budgetary rules established by the Maastricht Treaty, strengthened by the "Growth and Stability Pact", compel each euro-zone member state to a national deficit-reduction policy $^{6}$ To enforce budgetary discipline, the Treaty of Amsterdam specifies a number of mechanisms, both preventive and repressive, leading to financial penalties imposed on the faulty member state's central government.

An internal incentives problem stems from the fact that deficit and debt ratios apply to the consolidated budget of all public administration bodies, including central and local governments, whereas central authorities only are held responsible for violations. Without a mechanism for explicitly sharing the efforts made to curb deficits, local public administrations would conduct tax and budget policies without taking their impact on global deficits into account. To abide by the terms of European commitments, central governments should then design and implement coordination mechanisms, with the power to internalize budget externalities, and to ensure local budget policies' overall compatibility with national objectives.

In the following, Section 2 describes the model, the agents' utility functions and the land markets. Section 3 analyzes the central government's optimization problem under

\footnotetext{
${ }^{6}$ Compliance with budgetary rules can be assessed by comparing consolidated public deficits with reference ratios: public deficits must remain below $3 \%$ of GNP and public debt must not exceed $60 \%$ of GNP.
} 
conditions of complete (and symmetric) information; a Political-Economy version and a Welfare-Maximization version of the model are compared. Section 4 derives the optimal grant function, local taxes, and local public good productions in the asymmetric information case. Concluding remarks are gathered in Section 5.

\section{The model}

The economy consists of a State, run by a central government (also called the "center"), and a large number of local jurisdictions, with the same level in the hierarchy of public authorities, and administered by local governments (also called the Agents). Local governments represent citizen's preferences in a certain sense, to be made precise below. A local public good, financed through local taxes and grants from the center, is produced in each jurisdiction. Local public goods do not generate inter-jurisdictional spillovers. In each local jurisdiction,

there is a land (or real estate) market. Citizens "vote with their feet", and select the jurisdiction with the best bundle of local public goods, taxes and land prices. Any citizen moving in a given jurisdiction must buy (or rent) a piece of land (or a house) of nonzero size.

\subsection{The local governments' types}

Local jurisdictions differ only in a cost parameter $\beta$, hereafter called the local "type". The population of jurisdictions is described by a probability distribution of type $\beta$, the density of which is denoted $f(\beta)$, with c.d.f $F(\beta)$ and support $[\beta, \bar{\beta}$. Parameter $\beta$ captures various local characteristics which remain imperfectly observed by the central government, like geographical relief, geological aspects, local market conditions for production inputs, etc.

Let $q$ denote the quantity of a public good produced locally; its total production cost is defined as $C=c(\beta) q+k(q) \equiv(\beta-a) q+k(q)$, where $a$ denotes the local government's cost-reducing effort, and $k$ is an increasing, differentiably convex function of $q$ that doesn't depend on $\beta$. This cost of production doesn't depend on the number of consumers. In many countries, the central government has many pieces of information relative to local authorities' accounts, insofar as local budgetary documents are transmitted to the central 
administrative services, or publicly disclosed, and because the (central) Public Treasury acts as a tax collector, on behalf of the local governments. We then assume that the central government knows $k$ and always observes $C$ and $q$ ex post. It follows from this assumption that the unit $\operatorname{cost} c(\beta)=C / q-k(q) / q=\beta-a$ is observable. It also follows that efforts would be observable, if types were observable, for then $a=\beta-c(\beta)$. We also suppose that the center knows the local tax revenues.

Under asymmetric information, the center cannot decompose the local marginal cost into its type and effort components. An efficient local jurisdiction can pose as an inefficient one by exerting low effort. We assume that effort is costly for local governments. Denote $\Psi(a)$ the effort cost function; we assume that this function is continuously differentiable with $\Psi^{\prime}>0, \Psi^{\prime \prime}>0, \Psi(0)=0$.

\subsection{The citizens' utility function and free mobility equilibrium}

Let $N(\beta)$ denote the number of inhabitants in a jurisdiction of type $\beta$. There is a continuum of citizens. The total mass of citizens in the country is assumed fixed and normalized to one (without loss of generality). The following constraint thus holds:

$$
\int_{\underline{\beta}}^{\bar{\beta}} N(\beta) f(\beta) d \beta=1,
$$

(provided that $N$ is integrable, of course). From the point of view of citizens, jurisdiction $\beta$ is characterized by a land price $p(\beta)$, a level of local public good production $q(\beta)$ and a local tax $t(\beta)$. All citizens are assumed identical for simplicity. If a citizen chooses to settle in jurisdiction $\beta$, he or she chooses a quantity of land $x$, so as to maximize the quasi-linear utility function,

$$
U=u(q(\beta))-t(\beta)+v(x)-p(\beta) x
$$

where $u$ and $v$ are continuously differentiable, strictly increasing and concave functions. Due to the additive structure of utility, the demand for land is characterized by the first-order necessary (and sufficient) condition $v^{\prime}(x)=p$. We assume that there is one unit of land in each jurisdiction, it follows that in land market equilibrium, we must have $N(\beta) x=1$ in 
each jurisdiction, or

$$
p=v^{\prime}\left(\frac{1}{N(\beta)}\right) .
$$

The indirect utility of a citizen, located in a type $\beta$ jurisdiction, can therefore be rewritten,

$$
u(q(\beta))-t(\beta)+Z[N(\beta)]
$$

where by definition,

$$
Z(N)=v\left(\frac{1}{N}\right)-v^{\prime}\left(\frac{1}{N}\right) \frac{1}{N} .
$$

It is easy to check that $Z$ is decreasing (and invertible). Citizens being assumed identical and free to move from one jurisdiction to the other, there is a utility value $\bar{u}$, such that in free mobility equilibrium, for all $\beta$,

$$
u(q(\beta))-t(\beta)+Z[N(\beta)]=\bar{u}
$$

\subsection{The local governments' objective function}

The central government pays a grant $T(\beta)$ to each local jurisdiction. Each jurisdiction $\beta$ chooses a local (per capita) tax $t(\beta)$. Then, the number of inhabitants $N(\beta)$ is the local tax base, and $t(\beta) N(\beta)$ is the local tax revenue. From the point of view of the local government, local public good production has utility $S(q)$ and the local tax has an additively separable disutility $\Phi(t)$, where $S$ and $\Phi$ are differentiable, strictly increasing functions, with $S^{\prime \prime}<0$ and $\Phi^{\prime \prime}>0$.

The local government's utility is finally defined as follows:

$$
V=S(q)-\Phi(t)-\Psi(a)+T+t N-(\beta-a) q-k(q)
$$

There are two possible interpretations of this utility. If it is viewed as the local politician's objective, we get a model with a Political Economy flavor: $\Phi(t)$ is then the disutility of taxation for the politician, who fears that increasing local taxes might decrease his (her) reelection probability, and by the same token, he or she values local public goods, insofar as they increase his (her) electoral support. The rest of the expression is a rent, that is, the difference between total financial resources $T+t N$, and total costs $(\beta-a) q+k(q)+\Psi(a)$, 
expressed in money units, that the local politicians can use in various ways for campaigning, to curry favour with some groups of citizens, finance extravagant expenditures, etc.

If $S(q)$ is interpreted as social utility for the public good, and $\Phi(t)$ represents the social costs of local taxation, the same utility can be interpreted as a normative, Utilitarian objective, aggregating the local citizens' preferences over local public goods. Under this second, normative interpretation, the budget surplus $T+t N-(\beta-a) q-k$ is viewed as redistributed to citizens in one way or another, and $\Phi$ can be simply redefined as $\Phi(t, N)=$ $t N+\varphi(t)$. We can also set $S=N u(q)+N Z(N)$ to connect local government surplus and the citizens' real total surplus. A mix of the two interpretations is also legitimate, given that the scale of $S, \Phi$ and $\Psi$ can be adjusted to represent various weightings of money rents and the utility of local public policy $(q, t, a)$.

The effort cost $\Psi$ also supports several interpretations; it can represent the real cost of resources involved in improving efficiency, including the wages and bonuses paid to those who exert effort, and (or) it can be viewed as the aggregate private disutility of local civil servants, politicians, and possibly other citizens involved. We assume here that $\Psi$ does not appear as a cost in the public budget, which points to an interpretation in terms of private costs of cost-reduction efforts.

Local jurisdictions have a clear incentive to pump out money from the central government. The presence of $S(q)$ and $\Phi(t)$ can lead local powers to run a deficit as part of an optimal policy. There is no explicit budget constraint at the local level: local governments can freely run deficits. These deficits are financed by local public debt, reimbursed by future generations of local taxpayers. The local taste for rent will however limit the extent of deficits.

We finally assume that local jurisdictions cannot be forced to sustain arbitrarily large penalties, in the particular sense that utility $V$ cannot fall below a "reservation" level $\bar{V}$, for all type $\beta$. Let $I R(\beta)$ denote this participation, or individual rationality constraint, i.e. $V \geq \bar{V}$. This can again be interpreted in various ways. It can represent the politicians reservation utility, under which politicians prefer to resign and surrender the local rights of control to the central government. In some countries, bankrupt towns fall under the direct supervision of central government prefects, and therefore cease to exist as independent local 
authorities. Another interpretation is that constitutional rights forbid the central government to exploit local communities or districts arbitrarily.

\subsection{The central government's objective function and deficits}

To simplify notation, we will use the expectation operator $E$ each time there is an integral with respect to type $\beta$. More precisely, if $h$ is any integrable function of $\beta$, in the following, we denote,

$$
E(h)=\int_{\underline{\beta}}^{\bar{\beta}} h(\beta) f(\beta) d \beta .
$$

We assume for simplicity that the central government's expenditure is limited to the total sum of grants to local governments (introducing national taxes and national public goods in the model would not add anything essential). The central government's budget deficit can thus be expressed as $E(T)$, where the expectation represents the total sum of transfers to local governments. Given the terms of an international treaty, the central government is committed to keep consolidated public deficits, denoted $D$, below a given amount $\bar{D}$. The consolidated deficit of central and local governments can thus be computed as follows,

$$
D=E(T)+E[c q+k-t N-T]=E[c q+k-t N]
$$

If $D>\bar{D}$, in other words, if the consolidated deficit is above the limit, we assume that the central government pays an financial charge $r$ per unit of excess deficit. A possible interpretation is that the central government is fined by a supra-national authority. The amount of penalties is defined as

$$
P(D)=r \max (D-\bar{D}, 0)
$$

where $r \geq 0$. Local governments running a deficit exert a negative externality on the central government, whereas those who maintain a surplus exert a positive externality. We will focus on the interesting case in which $D>\bar{D}$, or $P(D)>0$. Remark that $P(D)$ may represent the financial and social costs and (or) the crowding-out effects of public debt. Parameter $r$ 
can also be interpreted as the interest on public debt, or as the Lagrange multiplier of the Public authorities' intertemporal budget constraint.

The central government's utility, denoted $W$, is defined as follows:

$$
W=-E(T)-P(D) .
$$

This is tantamount to assuming that the center minimizes the total sum of grants and financial costs on deficits. ${ }^{7}$

\section{Internal Stability Pact under Complete Information}

Assume for a moment that the central government perfectly and costlessly observes the type $\beta$, and the marginal cost $c$ of each local government. This is tantamount to assuming that the center also infers the efforts, since $c=\beta-a$. The central government would then choose $q(\beta), a(\beta), t(\beta)$, and $T(\beta)$, so as to maximise utility $W$, subject to the constraint that each local government's participation constraint is satisfied. Or, equivalently, assuming that $D>\bar{D}$

$$
\max _{q, t, a, T}-E(T)-r(D-\bar{D})
$$

subject to, for all type $\beta$,

\footnotetext{
${ }^{7}$ Note that the central government maximize their own utility, not the sum of the local constituencies' utilities. A typical strategy of the central government is to transfer attributions to local governments without transferring their full counterpart in terms of resources, thus freeing resources at the center that can be invested in the central politicians' reelection. The center's objective can thus also be interpreted as maximization of reelection probability, insofar as this probability is increasing with respect to central budget "surplus" (i.e., money that can be used in a discretionary way by the center). A limit of this simple model is of course that votes in favor of the central politicians can depend on the citizens' utility for local public goods, and on the amount of local taxes: voters can hold central politicians responsible for forcing local politicians to cut spending or raise local taxes. Our model could easily be extended to account for these effects by adding terms to $W$. A variant could for instance add a term of the form, $\delta E(V)$, where $\delta$ represents the weight of the local politicians' utilities in the central politician's objective function.
} 


$$
V=S(q)-\Phi(t)-\Psi(a)+T+t N-c q-k(q) \geq \bar{V}
$$

where to simplify notation, $q=q(\beta), a=a(\beta), c=c(\beta)=\beta-a(\beta), t=t(\beta), N=N(\beta)$, and $T=T(\beta)$. It is not difficult to check that the constraints $I R(\beta)$ will hold as equalities at the optimum. If the constraint was slack for some non-negligible subset of types, then the center could reduce transfers on a non-negligible set of types, and spare money. The center leaves no rents to local governments. We therefore get,

$$
T=-S(q)+\Phi(t)-t N+c q+k(q)+\Psi(a)+\bar{V}
$$

We then substitute this expression in the central government's objective function. After some easy algebra, the center's utility boils down to:

$$
W=E[S(q)-\Phi(t)-(1+r)(c q+k(q)-t N)-\Psi(a)]-\bar{V}+r \bar{D}
$$

which is equivalent to maximizing the sum of the local governments' utilities, once financial costs (or deficit penalties) are shared proportionally. This maximization problem is equivalent to that of a perfectly informed, central politician who adds all local interests together with an equal weight. In addition, all local governments will share the deficit penalties on an equal footing ${ }^{8}$. Remark that $r$ can be interpreted as the cost of public debt (if $\bar{D}=0$ ). This central government's objective should be maximized, subject to the constraint that the country is in free-mobility equilibrium.

\subsection{Necessary conditions for optimality under free mobility}

To solve this problem, remark that, $Z$ being a decreasing, differentiable function, it can be inverted, and given that in free-mobility equilibrium, $Z[N(\beta)]=\bar{u}-u(q(\beta))+t(\beta)$ for all $\beta$, we get,

$$
N(\beta)=Z^{-1}[\bar{u}-u(q(\beta))+t(\beta)]
$$

\footnotetext{
${ }^{8}$ The maximization of $W$ is also a way of characterizing a Pareto optimum in an economy in which economic agents are the local governments, plus the central government. If we have the normative interpretation of utilities in mind, maximizing $W$ is equivalent to maximizing the total sum of the citizens' utilities.
} 
for all $\beta$, where it is implicitly understood that $N$ is a function of parameter $\bar{u}$, to be determined in equilibrium. To simplify notation, denote

$$
n=Z^{-1}
$$

The equilibrium value of $\bar{u}$ is determined by the constraint,

$$
E\{n[\bar{u}-u(q)+t]\}=1
$$

For given functions $q(\beta), t(\beta)$, there is a unique value of $\bar{u}$ that solves the above equation, because $n$ is monotonic.

The central government's optimum problem is thus to maximize,

$$
E[S(q)-\Phi(t)-\Psi(a)-(1+r)(c q+k(q)-t n)]
$$

with respect to $q(),. a(),. t($.$) , and \bar{u}$, subject to (16). Introducing a constant Lagrange multiplier $\lambda$ for the population constraint, a standard method yields the first-order necessary conditions for an optimal contract (i.e., the "internal stability pact") between the central government and the local governments. Taking derivatives under the expectation operator with respect to $q, t, a$ for each $\beta$, and with respect to $\bar{u}$, and rearranging terms, yields the following four conditions,

$$
\begin{gathered}
\Psi^{\prime}(a)=(1+r) q, \\
S^{\prime}(q)=(1+r)\left(c+k^{\prime}\right)+[(1+r) t-\lambda] n^{\prime} u^{\prime} \\
\Phi^{\prime}(t)-[(1+r) t-\lambda] n^{\prime}=(1+r) n, \\
\lambda=\frac{(1+r) E\left(t n^{\prime}\right)}{E\left(n^{\prime}\right)},
\end{gathered}
$$

where of course $n$ and $n^{\prime}$ are functions of the argument $z=\bar{u}-u(q)+t$. Solving the first equation (i.e., (18)) gives effort $a^{*}$ as a function of $q^{*}$ for each type. The second and third conditions (i.e., (19) and (20)) then jointly determine $t^{*}$ and $q^{*}$ as a function of $\beta$ and $\bar{u}$. The value of $\lambda$ is given by (21), and the value of $\bar{u}$ is finally pinned down by the population constraint (16).

The interpretation of these optimality conditions is relatively easy. Equation (18) says that the optimal value of effort equates the marginal local disutility of effort with its marginal, 
cost-reduction value $(1+r) q$ in each jurisdiction. This cost-reduction value naturally takes the marginal cost of excess deficits into account (i.e., it depends on $r$ ). Multiplier $\lambda$ is the marginal value to the central government of one additional citizen in the country. Equation (21) says that $\lambda$ must also be equal to the average of local tax revenue losses due to mobilityinduced fiscal-base changes $n^{\prime}$, following a unit raise of $\bar{u}$ (i.e., $E\left(t n^{\prime}\right) / E\left(n^{\prime}\right)>0$ ). This term is multiplied by $(1+r)$, to take financial costs into account. Expression (19) says that at the optimum, the value to local government $\beta$ of increasing local public good production by one unit must be equal to marginal cost $(1+r)\left(c+k^{\prime}\right)$, minus the tax base gains due to immigration in local jurisdiction $\beta$, i.e., $(1+r) t n^{\prime} u^{\prime}<0$, plus the social cost $-\lambda n^{\prime} u^{\prime}$ inflicted to all other jurisdictions by the fact that $d N=-n^{\prime} u^{\prime}>0$ citizens would leave their jurisdiction to come to $\beta$. Equation (20) has a parallel interpretation and says that following a unit increase in local tax $d t=1$, the value of local tax revenue gains $(1+r) n$ must equal the marginal social cost of local taxation $\Phi^{\prime}$ plus the net marginal cost of migrations out of jurisdiction $\beta$, i.e., $-[(1+r) t-\lambda] n^{\prime}>0$. Again, the Lagrange multiplier $\lambda$ appears to reflect the fact that citizens who leave jurisdiction $\beta$ will increase the number of taxpayers and tax revenues in other jurisdictions, which must be taken into account by the central government. Note finally that (19) and (20) together imply the unusual condition,

$$
S^{\prime}(q)-(1+r)\left(c+k^{\prime}(q)\right)=u^{\prime}(q)\left[\Phi^{\prime}(t)-(1+r) n\right]
$$

If citizens are immobile, and uniformly distributed among jurisdictions, then $n^{\prime}=0$ and $n=1$ everywhere, so that optimality conditions boil down to $\Phi^{\prime}(t)=(1+r)$ and $S^{\prime}(q)=(1+r)\left(c+k^{\prime}(q)\right)$ : the tax rate and land prices are the same in every location, but, since $c=\beta-a$ is not a constant, local production varies from one jurisdiction to the next. This results in an unequal situation, in which citizens would like to move, if they were able to.

The system of equations (16), (18)-(21) is very hard to solve, because, due to citizens' free mobility, all optimal local policies are interdependent. Given that the expression of $\lambda$ involves the integral of a function of $q(\beta)$, and $t(\beta)$, we get a system of integral equations, that cannot be solved with the help of standard algebra and calculus, except in a few special cases. One such case is when the functions involved are linear-quadratic, so that their first 
derivatives are linear. To get a more complete understanding of the structure of central optima in our model, we now turn to the analysis of the linear quadratic case.

\subsection{The linear-quadratic case}

Assume first that the utility of land has the following hyperbolic shape,

$$
v(x)=-\frac{1}{2 \gamma x},
$$

where $\gamma>0$ is a parameter. Then, it is easy to check that $Z$ is linear, i.e.,

$$
Z(N)=-\frac{N}{\gamma}
$$

so that finally we get $n^{\prime}=-\gamma$. Assume in addition that $S(q)=s q$ with $s>0$ (note that adding a quadratic term to this specification would not lead to a really more general setting, because $k$ will be assumed quadratic). Given that citizens have the same preferences for

public goods, without much loss of generality, we can assume that $u$ is linear, and that $q$ is expressed in utility units, that is $u(q)=q$. We finally assume that all cost functions are quadratic: $\Phi(t)=(\varphi / 2) t^{2}, \Psi(a)=(\psi / 2) a^{2}$, and $k(q)=\left(c_{2} / 2\right) q^{2}$ where $\varphi, \psi, c_{2}>0$.

To simplify notation further, denote $\bar{q}=E(q), \bar{t}=E(t)$. Then, with this standard model, it is easy to see that equation $(21)$ yields $\lambda=(1+r) \bar{t}$. Equation (18) yields $a(\beta)=$ $(1 / \psi)(1+r) q(\beta)$. Then, the system of two equations (19) and (20) becomes linear, that is, after some rearrangement and substitution of (18) and (21), we get,

$$
\begin{gathered}
s=(1+r)\left[\beta+c_{2} q-(1+r) \psi^{-1} q\right]-\gamma(1+r)(t-\bar{t}), \\
\varphi t+\gamma(1+r)(t-\bar{t})=-\gamma(1+r)(\bar{u}-q+t) .
\end{gathered}
$$

The total population constraint (16) can now be rewritten,

$$
\gamma(\bar{q}-\bar{t}-\bar{u})=1
$$

Taking the expected values of (25) and (26) and solving for the optimal values $\left(\bar{q}^{*}, \bar{t}^{*}\right)$, we get, after some simplifications,

\section{Result 1.}

$$
\bar{q}^{*}=\frac{\psi}{(1+r)} \frac{[s-(1+r) E(\beta)]}{\left[\psi c_{2}-(1+r)\right]},
$$




$$
\bar{t}^{*}=\frac{1+r}{\varphi} .
$$

It is obvious that $\bar{q}^{*}$ will be positive if at the same time, $s$ is large enough with respect to the mean value of $\beta$ (which is a natural condition, for otherwise, the optimal production of local public goods could be zero, in some jurisdictions at least), $\Psi$ and $k$ is convex enough, that is, $c_{2} \psi>1+r$. We then immediately derive the equilibrium value of $\bar{u}$ from (27) as follows, $\bar{u}^{*}=\bar{q}^{*}-1 / \gamma-\bar{t}^{*}$. With these results (that we were able to obtain only because the model is linear-quadratic), we can rewrite (25)-(26) as follows,

$$
\begin{gathered}
{\left[(1+r) \psi^{-1}-c_{2}\right]\left(q-\bar{q}^{*}\right)+\gamma\left(t-\bar{t}^{*}\right)=[\beta-E(\beta)]} \\
\gamma(1+r)\left(q-\bar{q}^{*}\right)-[\varphi+2 \gamma(1+r)]\left(t-\bar{t}^{*}\right)=0
\end{gathered}
$$

This system has a unique solution, stated as Result 2, below. Straightforward algebra yields:

Result 2. Let $q^{*}, t^{*}$ denote the optimal solution under complete information, then,

$$
\begin{gathered}
q^{*}(\beta)-\bar{q}^{*}=\frac{-[\varphi+2 \gamma(1+r)]}{\Delta}(\beta-E(\beta)), \\
t^{*}(\beta)-\bar{t}^{*}=\frac{-\gamma(1+r)}{\Delta}(\beta-E(\beta)),
\end{gathered}
$$

where

$$
\Delta=\left[c_{2}-(1+r) \psi^{-1}\right][\varphi+2 \gamma(1+r)]-\gamma^{2}(1+r) .
$$

In addition, as a corollary,

$$
q^{*}(\beta)-\bar{q}^{*}=\frac{[\varphi+2 \gamma(1+r)]}{\gamma(1+r)}\left(t^{*}(\beta)-\bar{t}^{*}\right) ;
$$

and finally,

$$
a^{*}(\beta)=(1+r) \psi^{-1} q^{*}(\beta)
$$

Now, the interpretation of these results depends on the sign of the system determinant $\Delta$.

Result 3. If $\psi$ and $c_{2}$ are large enough, then, there exists an $\bar{r}$ such that if $0 \leq r<\bar{r}$, then $\Delta>0$, and as a result, more inefficient (i.e. high $\beta$ ) jurisdictions produce less, exert less effort, and tax less than efficient (i.e. low $\beta$ ) jurisdictions. Formally,

$$
\frac{\partial q^{*}(\beta)}{\partial \beta}<0 ; \quad \frac{\partial a^{*}(\beta)}{\partial \beta}<0 ; \quad \frac{\partial t^{*}(\beta)}{\partial \beta}<0 .
$$


A consequence of this result is that balanced-budget rules imposed on local governments are not optimal.

How does the optimal grant look like? It is defined with the help of $q^{*}(\beta), t^{*}(\beta)$, and expression (12), that is,

$$
\begin{aligned}
T^{*}(\beta)= & \bar{V}+\Phi\left(t^{*}(\beta)\right)+\Psi\left(a^{*}(\beta)\right)-S\left(q^{*}(\beta)\right)+k\left(q^{*}(\beta)\right) \\
& -t^{*}(\beta) n\left[\bar{u}^{*}-u\left(q^{*}(\beta)\right)+t^{*}(\beta)\right]+\left(\beta-a^{*}(\beta)\right) q^{*}(\beta) .
\end{aligned}
$$

This optimal grant function leaves no rents to local governments, whichever their type, so that $V^{*}=\bar{V}$ for all $\beta$. This will no longer be the case under asymmetric information. Finally, the utility of citizens is (by definition of free mobility equilibrium) the same everywhere, i.e. $U^{*}=\bar{u}$, for all $\beta$, but the price of land is not the same everywhere, i.e.,

$$
p^{*}(\beta)=v^{\prime}\left(\frac{1}{n\left[\bar{u}^{*}-u\left(q^{*}(\beta)\right)+t^{*}(\beta)\right]}\right) .
$$

Taking the derivative with respect to $\beta$, we get,

$$
\frac{\partial p^{*}(\beta)}{\partial \beta}=-\frac{v^{\prime \prime} n^{\prime}}{n^{2}}\left[\frac{\partial t^{*}(\beta)}{\partial \beta}-u^{\prime} \frac{\partial q^{*}(\beta)}{\partial \beta}\right]
$$

In the linear-quadratic framework, we get a decreasing price function, provided that $\Delta>0$, as in the statement of Result 3 above; i.e., since $v^{\prime \prime}<0$,

$$
\frac{\partial p^{*}(\beta)}{\partial \beta}=\frac{v^{\prime \prime} \gamma}{n^{2} \Delta}[\varphi+\gamma(1+r)]<0
$$

As a consequence, the more efficient the jurisdiction, the more densely populated.

We can finally discuss the impact of the degree of citizen mobility. This degree is parameterized by $\gamma$. When $\gamma$ goes to zero, the price of land becomes extremely sensitive to migrations, and as a result, citizens become immobile. When $\gamma=0$, Result 2 shows that taxes are the same everywhere. We can also show the following Result, the proof of which is straightforward.

Result 4. The variances of local public good production and of local taxes are increasing functions of the degree of mobility $\gamma$; formally,

$$
\frac{\partial}{\partial \gamma} \operatorname{Var}\left(q^{*}(\beta)\right)>0, \quad \frac{\partial}{\partial \gamma} \operatorname{Var}\left(t^{*}(\beta)\right)>0 .
$$




\subsection{Implementation of the optimum under complete information}

It is now easy to implement the optimum under conditions of complete information, provided that the central government has a reliable estimation of $\lambda$. The central government can subject all local governments to an incentive transfer schedule $\widetilde{T}$, depending on effort, production, local taxation, and population, which should be defined as follows,

$$
\widetilde{T}=-r(c q+k-t n)-n \lambda+M(\beta),
$$

where $M(\beta)$ is an appropriate function, not depending on $a, q, t$. It is not difficult to check that, when subjected to transfer $\widetilde{T}$, each local government $\beta$ chooses $t(\beta), q(\beta)$ and $a(\beta)$ so as to satisfy the first order conditions (18)-(20). The term $M(\beta)$ must be chosen so as to leave a zero rent to each type $\beta$ local government, once they have chosen the optimal values of effort, production and tax. The first term in the expression of $\widetilde{T}$ internalizes the vertical budget externality due to the existence of financial penalties, the second term internalizes the social cost of siphoning off the neighbor's tax base.

\subsection{The normative, benevolent-planner case}

We now derive the optimal solution in the normative version of the model, assuming that local governments want to maximize the total sum of their residents' utilities. To this end we simply change the analysis as follows: as indicated above, it is sufficient to set $\Phi=N t+\varphi(t)$, and $S=N u(q)+N Z(N)$. With these changes, the central government's objective becomes,

$$
E[N u(q)+N Z(N)-\varphi(t)-\Psi(a)-(1+r)(c q+k)+r N t] .
$$

But the free-mobility equilibrium condition yields $u(q)-t+Z(N)=\bar{u}$ for every citizen. Thus, the central government should maximize,

$$
E[n \bar{u}-\varphi(t)-\Psi(a)-(1+r)(c q+k-n t)],
$$

subject to the constraint $E(n)=1$, where $n$ is defined by (14)-(15) above. Let $\lambda$ denote the Lagrange multiplier of the constaint. The first-order conditions for optimality can be 
derived as before; we get the following four conditions:

$$
\begin{gathered}
\Psi^{\prime}(a)=(1+r) q, \\
-n^{\prime} u^{\prime} \bar{u}=(1+r)\left(c+k^{\prime}\right)+[(1+r) t-\lambda] n^{\prime} u^{\prime} \\
\varphi^{\prime}-n^{\prime} \bar{u}-[(1+r) t-\lambda] n^{\prime}=(1+r) n, \\
\lambda=\frac{1+(1+r) E\left(t n^{\prime}\right)}{E\left(n^{\prime}\right)}+\bar{u} .
\end{gathered}
$$

Note that conditions (19), (20) and (21) have changed. The local government's cost of taxation is now "endogenized". The marginal surplus terms are $-n^{\prime} u^{\prime} \bar{u}$ and $\varphi^{\prime}-n^{\prime} \bar{u}$ for production and taxation respectively, given that the economy must be in free-mobility equilibrium. We can now solve this system in the linear-quadratic case, exactly as specified above, assuming in addition that $\varphi(t)=(1 / 2) \varphi_{0} t^{2}$, with $\varphi_{0}>0$. We get the following results.

\section{Result 1B.}

$$
\begin{aligned}
\bar{q}^{*}=E\left(q^{*}\right) & =\frac{\psi[1-(1+r) E(\beta)]}{(1+r)\left[\psi c_{2}-(1+r)\right]}, \\
\bar{t}^{*} & =E\left(t^{*}\right)=\frac{r}{\varphi_{0}} .
\end{aligned}
$$

Remark that $\bar{q}^{*}>0$, if and only if $(1+r) E(\beta)<1$. This is a natural consequence of the normalization $u(q)=q$ : the marginal utility of the public good is constant and equal to 1 , so that, intuitively, average optimal production can be positive if the average marginal cost term $(1+r) E(\beta)$ is below 1 (we assume that the solution is interior). We get a regular, interior solution only if $\varphi_{0}>0$, as can be seen from (29b). Note that $\varphi_{0}$ has no reason to be equal to $\varphi$, which makes numerical comparisons with the Political Economy case less straightforward. Some algebra yields Result 2B.

Result 2B. Let $q^{*}, t^{*}$ denote the optimal solution under complete information, then,

$$
\begin{gathered}
q^{*}(\beta)-\bar{q}^{*}=\frac{-\varphi_{0}(\beta-E(\beta))}{\Delta_{2}}, \\
t^{*}(\beta)-\bar{t}^{*}=\frac{-(1+r) \gamma(\beta-E(\beta))}{\Delta_{2}},
\end{gathered}
$$

where

$$
\Delta_{2}=\varphi_{0}\left[c_{2}-(1+r) \psi^{-1}\right]-\gamma^{2}(1+r)
$$


and finally, effort $a^{*}(\beta)$ is the same as above. The system determinant $\Delta_{2}$ is positive if $\psi$, $\varphi_{0}$ and $c_{2}$ are large enough.

A quick comparison of Results $1,1 \mathrm{~B}$ and 2, 2B shows that the Welfare Maximization variant of the model is formally very close to the Political Economy variant — this is reassuring. The solutions possess some robust formal features, such as linearity with respect to $\beta-E(\beta)$. Yet, the solutions might produce different numerical results, because, even if $s=1, \Delta$ and $\Delta_{2}, \varphi$ and $\varphi_{0}$ are not necessarily the same.

\section{Internal Stability Pact under Asymmetric Informa- tion}

We can now start the study of the optimal internal stability pact under asymmetric information. The central government cannot observe $\beta$ and $a$ directly, but observes $t, C$ and $q$, or equivalently, observes $t, c=C / q$, and $q$. Given that $\beta$ is not observed by the center, the value of effort $a$ cannot be deduced. As in Laffont and Tirole (1986), the second-best optimal contract with local governments is a screening, self-selection mechanism, based on transfer formulae, i.e., in this context, it is an incentive grant schedule. We exclude the possibility of collusion among the numerous local governments.

We will rely on the Revelation Principle, saying that under asymmetric information, a direct revelation mechanism can do as well as any other, indirect, non-revealing mechanism, from the Principal's point of view.

A direct revelation mechanism (or internal stability pact) is an array of functions $(T(\widehat{\beta}), c(\widehat{\beta}), q(\widehat{\beta}), t(\widehat{\beta}))$, assumed differentiable, specifying a grant $T(\widehat{\beta})$, a marginal cost $c(\widehat{\beta})$, a tax $t(\widehat{\beta})$ and a production level $q(\widehat{\beta})$ for every possible report $\widehat{\beta}$ that the local government would like to make to the central government. A local government can manipulate the mechanism by inflating its reported $\operatorname{cost} \widehat{\beta}$ : this allows local authorities to provide less effort. More precisely, under the internal stability pact, to remain consistent with their claims, a local government with true type $\beta$ must exert a level of effort $\widehat{a}$ such that $c(\widehat{\beta})=\beta-\widehat{a}$, or equivalently, $\widehat{a}=\beta-\widehat{\beta}+a(\widehat{\beta})$, where of course, $a(\widehat{\beta})$ is the effort of a truthful type $\widehat{\beta}$. Given 
this deterministic link between efforts and observable marginal costs, the model is in fact equivalent to a pure adverse selection problem, in which the difficulty is to ensure truthful revelation of types.

\subsection{Incentive compatibility}

Let $\widehat{V}(\widehat{\beta} ; \beta)$ denote the utility of a type $\beta$ local government if they report that their type is $\widehat{\beta}$ :

$$
\begin{aligned}
\widehat{V}(\widehat{\beta} ; \beta) \equiv \quad & S[q(\widehat{\beta})]-\Phi(t(\widehat{\beta}))+T(\widehat{\beta}) \\
& +t(\widehat{\beta}) N(\widehat{\beta})-c(\widehat{\beta}) q(\widehat{\beta})-k(q(\widehat{\beta}))-\Psi[\beta-c(\widehat{\beta})]
\end{aligned}
$$

where $\beta-c(\widehat{\beta})$ is the required level of effort when posing as a type $\widehat{\beta}$, and by definition, $N(\widehat{\beta}) \equiv n[\bar{u}-u(q(\widehat{\beta}))+t(\widehat{\beta})]$. Denote simply

$$
\begin{aligned}
V(\beta) \equiv & \widehat{V}(\beta ; \beta) \equiv S[q(\beta)]-\Phi(t(\beta))+T(\beta) \\
& +t(\beta) N(\beta)-c(\beta) q(\beta)-k(q(\beta))-\Psi[\beta-c(\beta)]
\end{aligned}
$$

the utility of a truthful local government.

The internal stability pact $(T(\widehat{\beta}), c(\widehat{\beta}), q(\widehat{\beta}), t(\widehat{\beta}))$, is revealing if and only if

$$
\widehat{V}(\beta ; \beta) \geq \widehat{V}(\widehat{\beta} ; \beta)
$$

for all $(\beta, \widehat{\beta})$ in $[\beta, \bar{\beta}]^{2}$. There is an infinity of revelation or incentive compatibility constraints. We first show that this infinity of constraints is equivalent to a pair of simpler constraints. To this end, we rely on a fundamental Lemma, which is an adaptation of a well-known result in the Theory of Incentives (e.g., Laffont and Tirole (1986), Laffont and Martimort (2002)).

Lemma: The revelation constraints are equivalent to the following two conditions: for all $\beta$,

$$
V^{\prime}(\beta)=-\Psi^{\prime}(\beta-c(\beta))
$$




$$
c^{\prime}(\beta) \geq 0
$$

For the sake of completeness, we provide a proof of this result in the Appendix.

\subsection{The central government's second-best optimum problem}

The central government must now solve the following problem:

$$
\max _{q(\beta), t(\beta), a(\beta), T(\beta), \bar{u}}-E(T)-r(D-\bar{D})
$$

subject to $I R(\beta)$, i.e., $V(\beta) \geq \bar{V}, I C_{1}(\beta), I C_{2}(\beta)$, for all $\beta$, and the population constraint $E(N)=1$.

Since $V(\beta)$ is a non-increasing function of $\beta$, the participation constraint $I R(\beta)$ holds if and only if it holds for the highest type, i.e., $V(\bar{\beta}) \geq 0$. Integrating $I C_{1}(\beta)$, yields the expression of the local government's informational rent, that is,

$$
V(\beta)=\int_{\beta}^{\bar{\beta}} \Psi^{\prime}(x-c(x)) d x+V(\bar{\beta})
$$

The central government would like to pay the smallest possible amount of rent. It follows that $V(\bar{\beta})=\bar{V}$. Remark then that the most inefficient local government has a zero rent. Since $\Psi^{\prime}>0$, the other local government types receive an informational rent which is decreasing with $\beta$. Note that the rent of type $\beta$ is also increasing with the efforts of types $\beta^{\prime} \geq \beta$.

We now express the transfer $T(\beta)$ as a function of other variables; this yields,

$$
T(\beta)=V(\beta)-S(q(\beta))+\Phi(t(\beta))-t(\beta) N(\beta)+c(\beta) q(\beta)+k(q(\beta))+\Psi(\beta-c(\beta))
$$

Denote the rent of type $\beta$, as $r(\beta)=V(\beta)-\bar{V}$. The average rent $R$ paid by the central government is by definition $R=E(r)$. Using integration by parts ${ }^{9}$, we get,

\footnotetext{
${ }^{9} E(r)=\int r(\beta) f(\beta) d \beta=[r(\beta) F(\beta)]-\int r^{\prime}(\beta) F(\beta) d \beta$, that is, $E(r)=r(\bar{\beta}) F(\bar{\beta})-r(\underline{\beta}) F(\underline{\beta})+\int \Psi^{\prime}(a(\beta)) F(\beta) d \beta$. But $F(\underline{\beta})=0$, and $r(\bar{\beta})=0$.
} 


$$
R=\int_{\underline{\beta}}^{\bar{\beta}} \Psi^{\prime}(\beta-c(\beta)) F(\beta) d \beta .
$$

We then substitute the expressions for transfer and rent in the central government's objective function. After some straightforward simplifications, the center's optimization problem becomes,

$$
\begin{aligned}
& \max _{q(\beta), t(\beta), a(\beta), \bar{u}} \int_{\underline{\beta}}^{\bar{\beta}}\left[S(q(\beta))-\Phi(t(\beta))-\Psi(a(\beta))-\Psi^{\prime}(a(\beta)) \frac{F(\beta)}{f(\beta)}\right] f(\beta) d \beta \\
& -(1+r) \int_{\underline{\beta}}^{\bar{\beta}}[c(\beta) q(\beta)+k(q(\beta))-t(\beta) N(\beta)] f(\beta) d \beta
\end{aligned}
$$

where $a(\beta)=\beta-c(\beta)$, subject to the constraints $c^{\prime}(\beta) \geq 0$, and $E(N)=1$. Remark that if we define the function,

$$
\Lambda(a, \beta) \equiv \Psi(a)+\Psi^{\prime}(a) \frac{F(\beta)}{f(\beta)},
$$

the problem of finding the second-best optimal taxes, efforts, and local productions is the same as before, if we replace $\Psi$ with $\Lambda$ in (17), that is, the center should simply maximize,

$$
E[S-\Phi-\Lambda-(1+r)(c q+k-t n)]
$$

subject to $E(n)=1$, and $c^{\prime} \geq 0$. To solve this problem, we first neglect the constraint on $c^{\prime}$, write the first-order optimality conditions, and check that $I C_{2}$ holds afterwards. It follows that the first-order necessary conditions for a second-best optimal contract between the central and local governments can be written as (18)-(21) above, provided that $\Lambda$ is used instead of $\Psi$. The only change is that (18) must now be written,

$$
\Psi^{\prime}\left(a^{* *}(\beta)\right)+\Psi^{\prime \prime}\left(a^{* *}(\beta)\right) \frac{F(\beta)}{f(\beta)}=(1+r) q^{* *}(\beta)
$$

where $a^{* *}(\beta), q^{* *}(\beta), t^{* *}(\beta)$, denote the second-best optimal solution.

We can express the (second-best) optimal incentive grant schedule, denoted $T^{* *}$, as follows, 
Result 5. If $c^{\prime} \geq 0$ holds for all types, then, all local governments such that $\beta<\bar{\beta}$ enjoy informational rents at the optimum. The second-best optimal grant schedule is given by the following formula:

$$
\begin{aligned}
T^{* *}(\beta)= & \bar{V}+\int_{\beta}^{\bar{\beta}} \Psi^{\prime}(x-c(x)) d x-S\left(q^{* *}(\beta)\right)+\Phi\left(t^{* *}(\beta)\right) \\
& +\Psi\left(a^{* *}(\beta)\right)+\left(\beta-a^{* *}(\beta)\right) q^{* *}(\beta)+k\left(q^{* *}(\beta)\right) \\
& -t^{* *}(\beta) n\left[\bar{u}^{* *}-u\left(q^{* *}(\beta)\right)+t^{* *}(\beta)\right] .
\end{aligned}
$$

We need to check that $c^{\prime} \geq 0$ holds: we will do it later. To study the distortions induced by informational asymmetries without having to deal with the complex threedimensional comparative statics of the second-best solution, and again to clarify the exposition, we will focus on the linear-quadratic case ${ }^{10}$ (as defined in the preceding section). We can recycle Results 1 and 2, with some differences due to the change in the condition determining effort (i.e. (18) becoming (50)), to derive the second-best optimum.

For convenience, denote

$$
h(\beta) \equiv \frac{F(\beta)}{f(\beta)} .
$$

We can state the following.

\section{Result 6.}

$$
\begin{aligned}
\bar{q}^{* *}=E\left(q^{* *}\right) & =\frac{\psi[s-(1+r) E(\beta+h)]}{(1+r)\left[\psi c_{2}-(1+r)\right]}, \\
\bar{t}^{* *} & =E\left(t^{* *}\right)=\frac{1+r}{\varphi} .
\end{aligned}
$$

The only change in the expression of average production is that the mean type $E(\beta)$ has been replaced by the mean virtual type $E(h+\beta)$. Remark that, using integration by parts, $E(h)=\int F(x) d x=\bar{\beta}-E(\beta)$, and hence $E(\beta+h)=\bar{\beta}$. Having solved the first-order conditions for the average values of $q$ and $t$, we solve the complete system for the secondbest optimum $a^{* *}(\beta), q^{* *}(\beta), t^{* *}(\beta)$; using the same logic as above, straightforward algebra yields the following.

\footnotetext{
${ }^{10}$ Not much insight is lost by focusing on the linear-quadratic case, but a lot is gained in terms of understanding the solution's structure and economic intuition.
} 
Result 7. Under asymmetric information, assume that the second-best optimal solution is interior (i.e. $a, q, t>0$ for all $\beta$ ), then, we get,

$$
\begin{gathered}
q^{* *}(\beta)-\bar{q}^{* *}=\frac{-[\varphi+2 \gamma(1+r)]}{\Delta}[\beta+h-E(\beta+h)], \\
t^{* *}(\beta)-\bar{t}^{* *}=\frac{-\gamma(1+r)}{\Delta}[\beta+h-E(\beta+h)],
\end{gathered}
$$

where $\Delta$ is defined as in Result 2 above, and finally,

$$
a^{* *}(\beta)=\psi^{-1}(1+r) q^{* *}(\beta)-h(\beta) .
$$

Again, we find that the differences between first-best and second-best are entirely due to the replacement of types $\beta$, by Myerson's virtual types ${ }^{11}$, i.e., $\beta+F(\beta) / f(\beta)$.

Consider now the function $c^{* *}(\beta) \equiv \beta-a^{* *}(\beta)$. We must check that this function is non-decreasing. Remark that, using Result 7,

$$
\begin{aligned}
\frac{\partial c^{* *}(\beta)}{\partial \beta} & =1+h^{\prime}(\beta)-\frac{(1+r)}{\psi} \frac{\partial q^{* *}(\beta)}{\partial \beta} \\
& =\left(1+\frac{(1+r)}{\psi} \delta_{0}\right)\left(1+h^{\prime}(\beta)\right),
\end{aligned}
$$

where $\delta_{0}=\Delta^{-1}[\varphi+2 \gamma(1+r)]$. It is standard to assume in the literature on incentives, that $h^{\prime}>0$, or equivalently, that $f / F$ is a decreasing function. We can therefore state the following result.

Result 8. Assume that the second-best optimal solution is interior, then if $\Delta>0$, and $1+h^{\prime} \geq 0$, the monotonicity condition $I C_{2}(\beta)$ (i.e., $c^{* *}$ non-decreasing), holds for every $\beta$.

\subsection{The impact of informational asymmetries}

The second-best solution leads to the unusual conclusion that distortions occur at both ends of the type interval. To see this, compute,

$$
q^{* *}(\beta)-q^{*}(\beta)=\frac{-\psi E(h)}{\left[\psi c_{2}-(1+r)\right]}-\frac{[\varphi+2 \gamma(1+r)]}{\Delta}(h-E(h)) .
$$

\footnotetext{
${ }^{11}$ See Myerson (1981).
} 
We also get,

$$
t^{* *}(\beta)-t^{*}(\beta)=-\frac{\gamma(1+r)}{\Delta}(h-E(h)) .
$$

It is not difficult to check that there is a distortion "at the top", formally,

Result 9. If $\Delta>0$, there is a positive distortion at the lower end of the cost-type scale,

$$
q^{* *}(\underline{\beta})-q^{*}(\underline{\beta})>0
$$

i.e., the most efficient jurisdiction exhibits overproduction, as compared to first-best, and in addition,

$$
t^{* *}(\underline{\beta})-t^{*}(\underline{\beta})=\gamma(1+r) \Delta^{-1} E(h)>0,
$$

the most efficient jurisdictions exhibit over-taxation ${ }^{12}$.

Under the conditions of Result 8, we can try to summarize the differences between complete and asymmetric information as follows.

Result 10. Assuming that $\Delta>0$, the average second-best local public-good production $\bar{q}^{* *}$ is smaller than the corresponding first-best average $\bar{q}^{*}$. The average second-best local tax $\bar{t}^{* *}$ is the same than the first-best average $\bar{t}^{*}$, i.e.,

$$
\bar{q}^{* *}=E\left(q^{* *}\right)<\bar{q}^{*}=E\left(q^{*}\right), \quad \bar{t}^{* *}=E\left(t^{* *}\right)=\bar{t}^{*}=E\left(t^{*}\right)
$$

and if $h^{\prime}(\beta) \geq 0$, both taxation and local public good productions have a greater variance under asymmetric information:

$$
\operatorname{Var}\left(q^{* *}\right)>\operatorname{Var}\left(q^{*}\right), \quad \operatorname{Var}\left(t^{* *}\right)>\operatorname{Var}\left(t^{*}\right)
$$

Proof. The statement relative to expectations in Result 10 is an immediate consequence of Result 6. To obtain the property of increased variances, note that, using Results 2 and 6 , $\operatorname{Var}\left(t^{* *}\right)=\delta_{1}^{2} \operatorname{Var}(\beta+h)$, and $\operatorname{Var}\left(t^{*}\right)=\delta_{1}^{2} \operatorname{Var}(\beta)$. It follows that

$$
\operatorname{Var}\left(t^{* *}\right)=\operatorname{Var}\left(t^{*}\right)+\delta_{1}^{2}[\operatorname{Var}(h)+2 \operatorname{Cov}(\beta, h)],
$$

\footnotetext{
${ }^{12}$ This is related to Lockwood's (1999) "two-sided" distortions.
} 
where $\delta_{1}=-\Delta^{-1}(1+r) \gamma$. Since $h^{\prime} \geq 0$, we have $\operatorname{Cov}(\beta, h) \geq 0$, and thus $\operatorname{Var}(h)+$ $2 \operatorname{Cov}(\beta, h) \geq 0$, which yields the desired result for the variance of local taxes. The same reasoning, mutatis mutandis, yields the desired result concerning the variance of production. Q.E.D.

We conclude that the presence of asymmetric information worsens the situation for the citizens belonging to inefficient (high $\beta$ ) jurisdictions. Informational asymmetries increase the variance of taxes, keeping the average tax constant, and simultaneously decreases average production and increases the variance of the public good production. It then seems that the inequality among citizens increases as a consequence of informational asymmetries. But does the average utility level decrease? To see this precisely, let $\bar{u}^{*}$ denote the first-best utility level of citizens and $\bar{u}^{* *}$ denote the second-best utility level. Then, we must have,

$$
\bar{u}^{* *}=E\left(q^{* *}-t^{* *}+Z^{* *}\right)=\bar{q}^{* *}-\bar{t}^{* *}-\gamma^{-1} E\left(N^{* *}\right)
$$

with a similar expression for $\bar{u}^{*}$. Since $E(N)=1$ in either case, we get the following result.

Result 11. The citizens' average utility level is lower under asymmetric information than under complete information, formally,

$$
\bar{u}^{* *}-\bar{u}^{*}=\bar{q}^{* *}-\bar{q}^{*}<0 .
$$

The utility loss is entirely due to the decrease of public production on average, and the average effects of other factors (i.e., land prices and taxes) cancel each other.

At the same time, local politicians will be able to consume more rent in every constituency, except the least efficient ones. Effort distortions aim at reducing the cost of rents for the center: under asymmetric information, the internal stability pact is therefore the result of an optimal trade-off between informational rents and cost-reducing efforts. A powerful incentive scheme would push efforts to their first-best optimal levels, but would bleed the central government's budget white. Note that the analysis does not provide a standard result: this is due to free mobility. If citizens were immobile (and uniformly distributed among jurisdictions), the second-best structure would be more transparent, and would be exactly analogous to the solution of a Principal-Agent problem à la Laffont-Tirole (1986): all 
second-best optimal effort levels would be distorted downwards as compared to first best, and as a consequence, all second-best production levels would be distorted downwards, except for the most efficient jurisdictions, and local tax rates would be undistorted. The originality of the present approach comes from the interaction of local taxation and citizen mobility, more precisely from the presence of horizontal fiscal externalities induced by mobility. Local taxes, productions, efforts, and land prices are made interdependent in a non-trivial way, and what would otherwise have been a standard Principal-Agent model becomes a non-standard Principal-Multi-Agent structure.

\subsection{Implementation of the internal stability pact under asymmet- ric information}

We can use the Taxation Principle ${ }^{13}$, to show that the internal stability pact $\left(T^{* *}(\widehat{\beta}), c^{* *}(\widehat{\beta})\right.$, $q^{* *}(\widehat{\beta}), t^{* *}(\widehat{\beta})$ ) (which is a direct revealing mechanism), is equivalent to a nonlinear grant $G^{* *}(c)$, joint with a production requirement $Q^{* *}(c)$, and a local tax requirement $\tau^{* *}(c)$. This shows that the notion of type-reports of local governments to the center is more or less formal, since in fact, each government will choose in a menu $c \longmapsto\left(G^{* *}(c), Q^{* *}(c), \tau^{* *}(c)\right)$, depending on its observable marginal cost only.

Since $c^{* *}(\beta)$ is a strictly increasing function, it can be inverted. Let then $\beta=\beta^{* *}(c) \equiv$ $\left(c^{* *}\right)^{-1}(c)$ be this inverse function. We define the non-linear grant function as, $G^{* *}(c) \equiv$ $T^{* *}\left(\beta^{* *}(c)\right)$. And define $Q^{* *}(c)=q^{* *}\left(\beta^{* *}(c)\right), \tau^{* *}(c)=t^{* *}\left(\beta^{* *}(c)\right)$. When faced with this menu of choices, type $\beta$ chooses $c$ so as to get $c=\beta-a^{* *}(\beta)$.

Remark that the optimal solution does not really admit a decentralized choice of local taxes by local governments: each local government will be asked to choose in a menu, which determines the grant $G$, the local production $Q$, and the local tax rate $\tau$ simultaneously as a function of the observed unit cost $c$. Local jurisdictions are free in principle to choose their local tax, but the optimal incentives system will drive every rational local government to choose the second-best rate $t^{* *}$. Standard Principal-Agent, optimal regulation theories do not provide a justification for genuine fiscal decentralization — at least not is this simple

\footnotetext{
${ }^{13}$ Again, see Laffont and Martimort (2002).
} 
model.

\section{Conclusion}

We have studied the optimal contract linking a central government to local governments, under conditions of asymmetric information, when the aggregate deficit of the public sector must be reduced, due to financial costs or penalties. The problem is to understand how budgetary austerity will be "shared" with local governments, when governments are motivated by re-election perspectives and rents. Our results rely on optimal regulation theory, applied to a Principal-Multi-Agent framework. Due to the interdependence of jurisdictions through citizens' migrations, the solution obtained is not formally that of a standard Principal-Agent

problem. We characterize the shape of the second-best optimal grant schedule, when the cost of local public goods depends on unobservable characteristics and "efforts" of the local government. The second-best optimal production of local public goods and local tax rates are jointly distorted. The most efficient (low cost) jurisdictions produce more, tax more, experience higher land prices and attract more inhabitants than the less efficient (high cost) jurisdictions. Informational asymmetries increase the variance of both local tax rates and local productions of public goods, and the average utility and local public good production decreases, with respect to the complete information benchmark. 


\section{Appendix}

\section{Proof of the Lemma.}

The optimal report of an agent solves $\operatorname{Max}_{\widehat{\beta}} \widehat{V}(\widehat{\beta} ; \beta)$. The first-order necessary condition $\partial \widehat{V}(\widehat{\beta} ; \beta) / \partial \widehat{\beta}=0$ can be rewritten,

$$
\begin{aligned}
0= & S^{\prime}[q(\widehat{\beta})] q^{\prime}(\widehat{\beta})+T^{\prime}(\widehat{\beta})-c^{\prime}(\widehat{\beta}) q(\widehat{\beta})-c(\widehat{\beta}) q^{\prime}(\widehat{\beta}) \\
& -\Phi^{\prime}(t(\widehat{\beta})) t^{\prime}(\widehat{\beta})+(t(\widehat{\beta}) N(\widehat{\beta}))^{\prime}+\Psi^{\prime}[\beta-c(\widehat{\beta})] c^{\prime}(\widehat{\beta})
\end{aligned}
$$

Truthful revelation implies that the above relation holds for $\widehat{\beta}=\beta$, and we get :

$$
\begin{aligned}
0= & S^{\prime}[q(\beta)] q^{\prime}(\beta)+T^{\prime}(\beta)-c^{\prime}(\beta) q(\beta)-c(\beta) q^{\prime}(\beta) \\
& -\Phi^{\prime}(t(\beta)) t^{\prime}(\beta)+(t(\beta) N(\beta))^{\prime}+\Psi^{\prime}[\beta-c(\beta)] c^{\prime}(\beta),
\end{aligned}
$$

for all $\beta$. We now compute,

$$
\begin{aligned}
V^{\prime}(\beta) & =\frac{d \widehat{V}(\beta ; \beta)}{d \beta} \\
& =S^{\prime} q^{\prime}+T^{\prime}-c^{\prime} q-c q^{\prime}-\Phi^{\prime} t^{\prime}+(t N)^{\prime}+\Psi^{\prime}(\beta-c) c^{\prime}-\Psi^{\prime}(\beta-c) .
\end{aligned}
$$

And substituting the necessary condition for truthful revelation we find $I_{1}(\beta)$, that is, $V^{\prime}(\beta)=-\Psi^{\prime}(\beta-c(\beta))$. Now, the second-order necessary condition for truthful revelation holds if

$$
\frac{\partial^{2} \widehat{V}(\widehat{\beta} ; \beta)}{\partial \widehat{\beta}^{2}} \leq 0
$$

whenever $\widehat{\beta}=\beta$. Differentiating the first-order condition for truthful revelation and substituting in the second-order necessary condition, we find that the second-order necessary condition boils down to $-\Psi^{\prime \prime}[\beta-c(\beta)] c^{\prime}(\beta) \leq 0$. Given that we assume, $\Psi^{\prime \prime}>0$, this yields $c^{\prime}(\beta) \geq 0$, that is, $I C_{2}(\beta)$. We have proved that $I C_{1}(\beta)$ and $I C_{2}(\beta)$ are necessary for revelation. 
Conversely, global revelation constraints, i.e., $\widehat{V}(\beta ; \beta) \geq \widehat{V}(\widehat{\beta} ; \beta)$ for all $(\beta, \widehat{\beta})$, are equivalent to

$$
\int_{\widehat{\beta}}^{\beta} \frac{\partial \widehat{V}(x ; \beta)}{\partial x} d x \geq 0
$$

Using the fact that local incentive compatibility ensures $\partial \widehat{V}(\widehat{\beta} ; \widehat{\beta}) / \partial \widehat{\beta}=0$, we get,

$$
\int_{\widehat{\beta}}^{\beta}\left[\frac{\partial \widehat{V}(x ; \beta)}{\partial x}-\frac{\partial \widehat{V}(x ; x)}{\partial x}\right] d x=\int_{\widehat{\beta}}^{\beta} \int_{x}^{\beta} \frac{\partial^{2} \widehat{V}(x ; y)}{\partial y \partial x} d y d x \geq 0
$$

But,

$$
\frac{\partial^{2} \widehat{V}(x ; y)}{\partial y \partial x}=\frac{\partial}{\partial y}\left[\Psi^{\prime}[y-c(x)] c^{\prime}(x)\right]=\Psi^{\prime \prime}[y-c(x)] c^{\prime}(x) \geq 0 .
$$

We have proved that the local conditions $I C_{1}$ and $I C_{2}$ are sufficient for revelation. Q.E.D. 


\section{References}

Besfamille, M. (2002), "Local Public Works and Intergovernmental Transfers under Asymmetric Information", Journal of Public Economics, 88, 353-375.

Besley, T. and S. Coate (2003), "Centralized versus Decentralized Provision of Local Public Goods: A Political Economy Approach", Journal of Public Economics, 87, 2611-2637.

Boadway, R., Horiba, I, and R. Jha (1999), "The Provision of Public Services by Government Funded Decentralized Agencies", Public Choice, 100, 157-184.

Bordignon, M., Manasse, P. and G. Tabellini (2001), "Optimal Regional Redistribution under Asymmetric Information", American Economic Review, 91, 709-723.

Bucovetsky, S, Marchand, M. and P. Pestieau (1998), "Tax Competition and Revelation of Preferences for Public Expenditure", Journal of Urban Economics, 44, 367-390.

Cornes, R. C., and E. C. D. Silva (2002), "Local Public Goods, Inter-Regional Transfers and Private Information", European Economic Review, 46, 329-356.

Cremer, H., Marchand, M. and P. Pestieau (1996), "Inter-Regional Redistribution Through Tax Surcharge", International Tax and Public Finance, 3, 157-173.

Cremer, J., Estache, A. and P. Seabright (1996), "Decentralizing Public Services: What Can We Learn from the Theory of the Firm?", Revue d'Economie Politique, 106, 37-60.

Gilbert, G. and P. Picard (1996), "Incentives and the Optimal Size of Local Jurisdictions", European Economic Review, 40, 19-41.

Inman, R. P. and D. L. Rubinfeld (1997), "Rethinking Federalism", Journal of Economic Perspectives, 11, 43-64.

Laffont, J.J. and D. Martimort. (2002),. A Theory of Incentives: the Principal-Agent Model, Princeton University Press, Princeton.

Laffont, J.J. and J. Tirole. (1986),. "Using Cost Observation to Regulate Firms". Journal of Political Economy, 94, 614-641. 
Laffont, J.J. and J. Tirole. (1993),. A Theory of Incentives in Procurement and Regulation, MIT Press, Cambridge, Massachusetts.

Laffont, J.J. and W. Zantman (2002), "Information Acquisition, Political Game and the Delegation of Authority", European Journal of Political Economy, 18, 407-428.

Lockwood, B. (1999), "Inter-Regional Insurance", Journal of Public Economics, 72, 1-37.

Lockwood, B. (2002), "Distributive Politics and the Costs of Centralization", Review of Economic Studies, 69, 313-337.

Myerson, R. B. (1981), "Optimal Auction Design", Mathematics of Operations Research, 6, 58-73.

Oates, W. E. (1972), Fiscal Federalism, Harcourt Brace Jovanovitch, New York.

Oates , W. E. (2004), "Toward a Second-Generation Theory of Fiscal Federalism", manuscript, University of Maryland, Maryland.

Persson, T. and G. Tabellini (1996), "Federal Fiscal Constitutions: Risk Sharing and Moral Hazard", Econometrica, 64, 623-646.

Raff H. and J. D. Wilson (1997), "Income Redistribution with Well-Informed Local Governments", International Tax and Public Finance, 4, 7-27.

Scotchmer, S. (2002), "Local Public Goods and Clubs", Chapter 29 in Auerbach and Feldstein eds., Handbook of Public Economics, vol. 4, Elsevier, Amsterdam.

Seabright, P. (1996), "Accountability and Decentralization in Government: An Incomplete Contracts Model", European Economic Review, 40, 61-89.

Tiebout, C. M. (1956), "A Pure Theory of Local Expenditures", Journal of Political Economy, 64, 416-424. 


\section{CESifo Working Paper Series}

(for full list see www.cesifo-group.de)

1497 Panos Hatzipanayotou and Michael S. Michael, Migration, Tied Foreign Aid and the Welfare State, July 2005

1498 Agata Antkiewicz and John Whalley, BRICSAM and the Non-WTO, July 2005

1499 Petr Hedbávný, Ondřej Schneider and Jan Zápal, A Fiscal Rule that has Teeth: A Suggestion for a 'Fiscal Sustainability Council' underpinned by the Financial Markets, July 2005

1500 J. Atsu Amegashie and Marco Runkel, Sabotaging Potential Rivals, July 2005

1501 Heikki Oksanen, Actuarial Neutrality across Generations Applied to Public Pensions under Population Ageing: Effects on Government Finances and National Saving, July 2005

1502 Xenia Matschke, Costly Revenue-Raising and the Case for Favoring Import-Competing Industries, July 2005

1503 Horst Raff and Nicolas Schmitt, Why Parallel Trade may Raise Producers Profits, July 2005

1504 Alberto Bisin and Piero Gottardi, Efficient Competitive Equilibria with Adverse Selection, July 2005

1505 Peter A. Zadrozny, Necessary and Sufficient Restrictions for Existence of a Unique Fourth Moment of a Univariate GARCH(p,q) Process, July 2005

1506 Rainer Niemann and Corinna Treisch, Group Taxation, Asymmetric Taxation and Cross-Border Investment Incentives in Austria, July 2005

1507 Thomas Christiaans, Thomas Eichner and Ruediger Pethig, Optimal Pest Control in Agriculture, July 2005

1508 Biswa N. Bhattacharyay and Prabir De, Promotion of Trade and Investments between China and India: The Case of Southwest China and East and Northeast India, July 2005

1509 Jean Hindriks and Ben Lockwood, Decentralization and Electoral Accountability: Incentives, Separation, and Voter Welfare, July 2005

1510 Michelle R. Garfinkel, Stergios Skaperdas and Constantinos Syropoulos, Globalization and Domestic Conflict, July 2005

1511 Jesús Crespo-Cuaresma, Balázs Égert and Ronald MacDonald, Non-Linear Exchange Rate Dynamics in Target Zones: A Bumpy Road towards a Honeymoon - Some Evidence from the ERM, ERM2 and Selected New EU Member States, July 2005 
1512 David S. Evans and Michael Salinger, Curing Sinus Headaches and Tying Law: An Empirical Analysis of Bundling Decongestants and Pain Relievers, August 2005

1513 Christian Keuschnigg and Martin D. Dietz, A Growth Oriented Dual Income Tax, July 2005

1514 Fahad Khalil, David Martimort and Bruno Parigi, Monitoring a Common Agent: Implications for Financial Contracting, August 2005

1515 Volker Grossmann and Panu Poutvaara, Pareto-Improving Bequest Taxation, August 2005

1516 Lars P. Feld and Emmanuelle Reulier, Strategic Tax Competition in Switzerland: Evidence from a Panel of the Swiss Cantons, August 2005

1517 Kira Boerner and Silke Uebelmesser, Migration and the Welfare State: The Economic Power of the Non-Voter?, August 2005

1518 Gabriela Schütz, Heinrich W. Ursprung and Ludger Wößmann, Education Policy and Equality of Opportunity, August 2005

1519 David S. Evans and Michael A. Salinger, Curing Sinus Headaches and Tying Law: An Empirical Analysis of Bundling Decongestants and Pain Relievers, August 2005

1520 Michel Beine, Paul De Grauwe and Marianna Grimaldi, The Impact of FX Central Bank Intervention in a Noise Trading Framework, August 2005

1521 Volker Meier and Matthias Wrede, Pension, Fertility, and Education, August 2005

1522 Saku Aura and Thomas Davidoff, Optimal Commodity Taxation when Land and Structures must be Taxed at the Same Rate, August 2005

1523 Andreas Haufler and Søren Bo Nielsen, Merger Policy to Promote 'Global Players'? A Simple Model, August 2005

1524 Frederick van der Ploeg, The Making of Cultural Policy: A European Perspective, August 2005

1525 Alexander Kemnitz, Can Immigrant Employment Alleviate the Demographic Burden? The Role of Union Centralization, August 2005

1526 Baoline Chen and Peter A. Zadrozny, Estimated U.S. Manufacturing Production Capital and Technology Based on an Estimated Dynamic Economic Model, August 2005

1527 Marcel Gérard, Multijurisdictional Firms and Governments' Strategies under Alternative Tax Designs, August 2005

1528 Joerg Breitscheidel and Hans Gersbach, Self-Financing Environmental Mechanisms, August 2005 
1529 Giorgio Fazio, Ronald MacDonald and Jacques Mélitz, Trade Costs, Trade Balances and Current Accounts: An Application of Gravity to Multilateral Trade, August 2005

1530 Thomas Christiaans, Thomas Eichner and Ruediger Pethig, A Micro-Level 'Consumer Approach' to Species Population Dynamics, August 2005

1531 Samuel Hanson, M. Hashem Pesaran and Til Schuermann, Firm Heterogeneity and Credit Risk Diversification, August 2005

1532 Mark Mink and Jakob de Haan, Has the Stability and Growth Pact Impeded Political Budget Cycles in the European Union?, September 2005

1533 Roberta Colavecchio, Declan Curran and Michael Funke, Drifting Together or Falling Apart? The Empirics of Regional Economic Growth in Post-Unification Germany, September 2005

1534 Kai A. Konrad and Stergios Skaperdas, Succession Rules and Leadership Rents, September 2005

1535 Robert Dur and Amihai Glazer, The Desire for Impact, September 2005

1536 Wolfgang Buchholz and Wolfgang Peters, Justifying the Lindahl Solution as an Outcome of Fair Cooperation, September 2005

1537 Pieter A. Gautier, Coen N. Teulings and Aico van Vuuren, On-the-Job Search and Sorting, September 2005

1538 Leif Danziger, Output Effects of Inflation with Fixed Price- and Quantity-Adjustment Costs, September 2005

1539 Gerhard Glomm, Juergen Jung, Changmin Lee and Chung Tran, Public Pensions and Capital Accumulation: The Case of Brazil, September 2005

1540 Yvonne Adema, Lex Meijdam and Harrie A. A. Verbon, The International Spillover Effects of Pension Reform, September 2005

1541 Richard Disney, Household Saving Rates and the Design of Social Security Programmes: Evidence from a Country Panel, September 2005

1542 David Dorn and Alfonso Sousa-Poza, Early Retirement: Free Choice or Forced Decision?, September 2005

1543 Clara Graziano and Annalisa Luporini, Ownership Concentration, Monitoring and Optimal Board Structure, September 2005

1544 Panu Poutvaara, Social Security Incentives, Human Capital Investment and Mobility of Labor, September 2005

1545 Kjell Erik Lommerud, Frode Meland and Odd Rune Straume, Can Deunionization Lead to International Outsourcing?, September 2005 
1546 Robert Inklaar, Richard Jong-A-Pin and Jakob de Haan, Trade and Business Cycle Synchronization in OECD Countries: A Re-examination, September 2005

1547 Randall K. Filer and Marjorie Honig, Endogenous Pensions and Retirement Behavior, September 2005

1548 M. Hashem Pesaran, Til Schuermann and Bjoern-Jakob Treutler, Global Business Cycles and Credit Risk, September 2005

1549 Ruediger Pethig, Nonlinear Production, Abatement, Pollution and Materials Balance Reconsidered, September 2005

1550 Antonis Adam and Thomas Moutos, Turkish Delight for Some, Cold Turkey for Others?: The Effects of the EU-Turkey Customs Union, September 2005

1551 Peter Birch Sørensen, Dual Income Taxation: Why and how?, September 2005

1552 Kurt R. Brekke, Robert Nuscheler and Odd Rune Straume, Gatekeeping in Health Care, September 2005

1553 Maarten Bosker, Steven Brakman, Harry Garretsen and Marc Schramm, Looking for Multiple Equilibria when Geography Matters: German City Growth and the WWII Shock, September 2005

1554 Paul W. J. de Bijl, Structural Separation and Access in Telecommunications Markets, September 2005

1555 Ueli Grob and Stefan C. Wolter, Demographic Change and Public Education Spending: A Conflict between Young and Old?, October 2005

1556 Alberto Alesina and Guido Tabellini, Why is Fiscal Policy often Procyclical?, October 2005

1557 Piotr Wdowinski, Financial Markets and Economic Growth in Poland: Simulations with an Econometric Model, October 2005

1558 Peter Egger, Mario Larch, Michael Pfaffermayr and Janette Walde, Small Sample Properties of Maximum Likelihood Versus Generalized Method of Moments Based Tests for Spatially Autocorrelated Errors, October 2005

1559 Marie-Laure Breuillé and Robert J. Gary-Bobo, Sharing Budgetary Austerity under Free Mobility and Asymmetric Information: An Optimal Regulation Approach to Fiscal Federalism, October 2005 